\title{
Maintenance Mechanism for the Teleconnection Pattern over the High Latitudes of the Eurasian Continent in Summer
}

\author{
XINYU LI \\ College of Oceanography, Hohai University, Nanjing, China
}

RIYU LU

State Key Laboratory of Numerical Modeling for Atmospheric Sciences and Geophysical Fluid Dynamics, Institute of Atmospheric Physics, Chinese Academy of Sciences, and College of Earth and Planetary Sciences, University of the Chinese Academy of Sciences, Beijing, China

\section{RICHARD J. GREATBATCH}

Ocean Circulation and Climate Dynamics, GEOMAR Helmholtz Centre for Ocean Research Kiel, and Faculty of Mathematics and Natural Sciences, University of Kiel, Kiel, Germany

\section{GEN LI}

College of Oceanography, Hohai University, Nanjing, China

\section{XiAOWEI HONG}

College of Earth and Planetary Sciences, University of the Chinese Academy of Sciences, and Climate Change Research Center and Nansen-Zhu International Research Centre, Institute of Atmospheric Physics, Chinese Academy of Sciences, Beijing, China

(Manuscript received 19 May 2019, in final form 21 October 2019)

\begin{abstract}
There is a zonally oriented teleconnection pattern over the high-latitude Eurasian continent, which is maintained through baroclinic energy conversion. In this study, we investigate the unique features of the maintenance mechanism of this teleconnection. It is found that the baroclinic energy conversion is most efficient in both the midtroposphere and the lower troposphere, and that the baroclinic energy conversion in the lower troposphere is comparable to that in the midtroposphere. Further results indicate that the basic state plays a crucial role in the baroclinic energy conversion. For both the middle and lower troposphere, the atmospheric stability is low and the Coriolis parameter is large over high-latitude Eurasia, favoring strong baroclinic energy conversion. Particularly, in the lower troposphere, the atmospheric stability exhibits a clear land-sea contrast, favoring baroclinic energy conversion over the continents rather than the oceans. Furthermore, in the lower troposphere, the in-phase configuration of the meridional wind and temperature anomalies, which results from the strong meridional gradient of mean temperature around the north edge of the Eurasian continent, also significantly contributes to baroclinic energy conversion. This study highlights the role of the basic state of temperature rather than zonal wind in maintaining the high-latitude teleconnection through baroclinic energy conversion.
\end{abstract}

\section{Introduction}

Summer climate variability over the Eurasian continent is greatly affected by atmospheric teleconnection patterns or Rossby waves (e.g., Lu et al. 2002; Wu 2002;

\footnotetext{
Corresponding author: Dr. Xinyu Li, lixinyu@hhu.edu.cn
}

Ding and Wang 2005; Folland et al. 2009; Bladé et al. 2012; Ding et al. 2011; Hong et al. 2018; Li and Ruan 2018; P. Xu et al. 2019). Various teleconnection patterns have been used to explain regional anomalous rainfall (Wang 1992; Iwao and Takahashi 2006, 2008; Chen and Huang 2012; Sun and Wang 2012; Lin 2014; Li and Lu 2017; Lin et al. 2017a; Li and Lu 2018; Wang et al. 2018), 
temperature (Greatbatch and Rong 2006; Hong et al. 2017), and extreme events (Cassou et al. 2005; Wulff et al. 2017; K. Xu et al. 2019). Therefore, understanding the mechanisms responsible for these teleconnections is of scientific significance and has important implications for the prediction of weather and climate over Eurasia.

Many teleconnection patterns or Rossby waves in summer appear over a wide range of latitudes over the Eurasian continent, and thus can act as a dynamical link between the tropics and extratropics. Some of these teleconnections can be excited by tropical forcing and propagate poleward (e.g., Hoskins and Karoly 1981; Nitta 1987; Huang and Sun 1992; Wulff et al. 2017). Some examples are 1) the well-known Pacific-Japan pattern (Nitta 1987) or East Asian-Pacific pattern (Huang and Sun 1992), which is associated with the anomalous convection over the tropical western North Pacific (Nitta 1986, 1987; Lu and Dong 2001; Lu 2004; Kosaka et al. 2011), and 2) the summer east Atlantic mode introduced by Wulff et al. (2017), which can be forced by diabatic heating anomalies of opposing signs in the tropical Pacific and Caribbean. On the other hand, some circulation modes exist without clear tropical forcing, such as the summer North Atlantic Oscillation (Feldstein 2007; Folland et al. 2009) and the Eurasian pattern during summer (Yang 1992; Yang and Huang 1992; Lee et al. 2005; Yoon and Yeh 2010).

Another kind of teleconnection pattern is confined to a limited range of latitudes over the Eurasian continent during summer. The so-called Silk Road pattern (SRP) is such a kind of teleconnection ( $\mathrm{Lu}$ et al. 2002; Enomoto et al. 2003; Yasui and Watanabe 2010; Chen and Huang 2012; Hong and Lu 2016; Zhou et al. 2019). The SRP propagates zonally in the midlatitudes across the Eurasian continent along the upper-tropospheric Asian westerly jet, which acts as a waveguide and confines the waves within it (Hoskins and Ambrizzi 1993; Ambrizzi et al. 1995; Branstator and Teng 2017). The maintenance mechanism of the SRP can be explained by the interaction between stationary waves and the basic flow (Sato and Takahashi 2006; Kosaka et al. 2009; Yasui and Watanabe 2010; Song et al. 2013). The perturbations associated with the SRP can efficiently extract kinetic energy from the basic flow through barotropic energy conversion and available potential energy through baroclinic energy conversion. Another important, but secondary, factor affecting the SRP is tropical heating anomalies, for instance, rainfall anomalies associated with the Indian summer monsoon (Ding and Wang 2005; Sato and Takahashi 2006; Ding et al. 2011; Chen and Huang 2012; Greatbatch et al. 2013).

Teleconnections or Rossby waves also appear at high latitudes over the Eurasian continent in summer, as shown in previous studies, which focused on climate anomalies over various regions and investigated the circulation anomalies responsible for the climate anomalies (Wakabayashi and Kawamura 2004; Fukutomi et al. 2004; Iwao and Takahashi 2006, 2008; Lin 2014; Lin et al. 2017b). For example, Fukutomi et al. (2004) identified an out-of-phase relationship in precipitation between eastern and western Siberia, and indicated that this out-ofphase relationship is the result of stationary waves over northern Eurasia. Nakamura and Fukamachi (2004) found that abnormal coolness over eastern Japan is greatly affected by the Okhotsk high, and the Okhotsk high can be attributed to a stationary Rossby wave that originates from northern Europe and extends to the Far East. Among the four relevant teleconnection patterns responsible for anomalous summer climate in Japan extracted by Wakabayashi and Kawamura (2004), two appear over northern Eurasia. Iwao and Takahashi (2006) identified a north-south seesaw pattern in July precipitation between northeast Asia and Siberia, and found that this seesaw pattern is associated with circulation anomalies over northern Eurasia as well as those along the upper-tropospheric midlatitude westerly jet. These studies demonstrated that the teleconnections exist in the high latitudes over the Eurasian continent and play an important role in affecting regional climate in summer.

Recent studies presented more evidence of teleconnection patterns in the high latitudes of the Eurasian continent. The summer east Atlantic mode identified by Wulff et al. (2017) is a teleconnection pattern that appears over the North Pacific, North America, North Atlantic, and the high-latitude western Eurasian continent. Wulff et al. (2017) suggested that this mode can be forced by diabatic heating anomalies in the tropics. $\mathrm{Li}$ and Ruan (2018) introduced a teleconnection pattern over the North Atlantic and the high latitudes of the Eurasian continent, and explained this teleconnection pattern in terms of stationary Rossby waves originating over the subtropical North Atlantic. These teleconnections include significant circulation anomalies over the highlatitude Eurasian continent, but they appear over a wide range of latitudes, and are attributed to tropical or subtropical forcings. By contrast, P. Xu et al. (2019) reported a zonally oriented teleconnection pattern propagating from the British Isles over the high-latitude Eurasian continent, and indicated that this teleconnection pattern shows only a loose relationship to external forcing. They suggested that this teleconnection pattern can be maintained through baroclinic energy conversion from the basic flow, while the barotropic energy conversion is much less efficient.

The present study aims to dig further into the physical mechanism for the occurrence and maintenance of the 
high-latitude teleconnection pattern over the Eurasian continent. We focus on the role of the basic state, rather than tropical and subtropical forcings. Actually, as a kind of basic state, the basic flow is very weak over the high-latitude Eurasian continent, and thus exhibits only weak shear both horizontally and vertically. This is in a sharp contrast to the midlatitude Eurasian continent, where the basic flow exhibits a strong shear both horizontally and vertically, corresponding to the strong Asian westerly jet in the upper troposphere. One can attribute the weak barotropic energy conversion suggested by P. Xu et al. (2019) to the weak horizontal shear of basic flows in the high-latitude Eurasian continent. However, how does the weak vertical shear of the basic flow induce the baroclinic energy conversion, which efficiently maintains the high-latitude teleconnection over the Eurasian continent? What are the unique features of the basic state favoring the occurrence and maintenance of the teleconnection over the high latitudes of the Eurasian continent? In this study, we explore these issues.

The rest of this paper is arranged as follows. Section 2 describes the data and methods. Section 3 presents the features of high-latitude Eurasian teleconnection pattern and the associated baroclinic energy conversion. The results in this section indicate that the teleconnection pattern can effectively extract available potential energy from the basic flow in both the middle and lower troposphere. Therefore, section 4 further illustrates the baroclinic energy conversion in the middle and lower troposphere, respectively. Section 5 is devoted to a summary and discussion.

\section{Dataset and methods}

The primary dataset used in this study is the monthly ERA-Interim dataset (Dee et al. 2011), on a horizontal resolution of $1.5^{\circ} \times 1.5^{\circ}$. The analyzed time span is selected from 1979 to 2017. We also employed the National Centers for Environmental Prediction (NCEP)-National Center for Atmospheric Research (NCAR) reanalysis dataset (Kalnay et al. 1996) and the Japanese 55-Year Reanalysis (JRA-55) dataset (Kobayashi et al. 2015) to repeat the main analyses and obtained similar results. In this study, we focus on the summer mean, which refers to the averages over June-August (JJA).

The main statistical methods used in the present study are empirical orthogonal function (EOF) analysis, regression analysis, and correlation analysis. The method proposed by North et al. (1982) is used to test the statistical significance in the EOF analysis, and the Student's $t$ test is used to determine the statistical significance in the analyzed results.
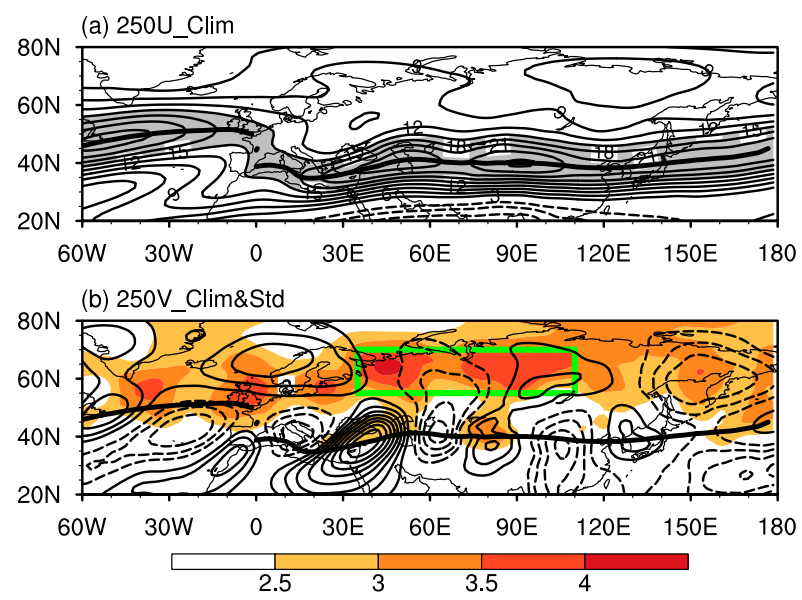

FIG. 1. (a) Climatological mean of $250-\mathrm{hPa}$ zonal wind and (b) meridional wind in JJA. Contour intervals are $3.0 \mathrm{~m} \mathrm{~s}^{-1}$ in (a) and $1.0 \mathrm{~m} \mathrm{~s}^{-1}$ in (b). Zero contours are omitted. Gray shading in (a) indicates zonal wind is greater than $15.0 \mathrm{~m} \mathrm{~s}^{-1}$. Color shadings in (b) denote the standard deviation of $250-\mathrm{hPa}$ meridional wind. The bold black lines represent the climatological jet axis during summer. The domain marked by the green rectangle in (b) is used for the latter EOF analyses.

\section{The high-latitude Eurasian teleconnection pattern and the associated baroclinic energy conversion}

Figure 1 shows the climatological JJA-mean horizontal winds at $250 \mathrm{hPa}$. Here, we use $250 \mathrm{hPa}$ to represent the upper troposphere rather than $200 \mathrm{hPa}$, considering that the thickness of troposphere in the high latitudes is thinner than that in the midlatitudes. The basic flow in the high latitudes shows distinctly different features from that in the midlatitudes. For the zonal winds (Fig. 1a), the westerly jet stream spans across the North Atlantic and the midlatitude Eurasian continent, with strong meridional shear to the north and south of the jet axis. Here, the jet axis is determined as the first derivative of zonal winds being zero. Over the high-latitude Eurasian continent, however, the zonal wind shows much more uniform features, with very weak zonal and meridional gradients. For the meridional winds (Fig. 1b), the midlatitudes are characterized by alternatively southerly and northerly flows, with maximum amplitudes along the Asian westerly jet. Over the high-latitude Eurasian continent, by contrast, the meridional winds are weak. However, the meridional winds show strong standard deviations, indicating that the upper-tropospheric meridional winds over the region exhibit large interannual variability. The standard deviations are much stronger in the high latitudes than the midlatitudes. It is notable that the cells of large interannual variability at the high latitudes do not correspond to 
the cells of the climatological strong northerlies or southerlies.

Figure 2 shows the leading mode of 250 -hPa JJAmean meridional winds obtained by EOF analysis within the domain $55^{\circ}-70^{\circ} \mathrm{N}, 35^{\circ}-110^{\circ} \mathrm{E}$, where the standard deviations of meridional winds are basically larger than $3.50 \mathrm{~m} \mathrm{~s}^{-1}$ (Fig. 1b). Prior to EOF analysis, the raw data are weighted by the square root of the cosine of latitude to obtain equal weight to equal areas. The leading mode explains nearly half of the total interannual variance of meridional winds $(49.3 \%)$ and is significantly distinguished from the higher modes according to North et al. (1982). The analysis domain is deliberately separated from those used for the SRP analyses over midlatitudes conducted by previous authors (e.g., Yasui and Watanabe 2010; Hong and Lu 2016). The domain is also smaller than those used specially for high-latitude wave trains by previous authors (Xie and Kosaka 2016; P. Xu et al. 2019), since we attempt to highlight the main body of the wave train. In fact, the present results are not sensitive to the precise choice of EOF domain. As discussed in later analyses, the wave train can most effectively extract available potential energy from the basic flow for its growth and maintenance within the chosen analysis domain. In addition, we also conducted EOF analyses on the meridional wind and geopotential height at other levels, such as the geopotential height at $500 \mathrm{hPa}$ or the meridional wind at $925 \mathrm{hPa}$, and obtained very similar wave trains and principal components (not shown). This is associated with the equivalent barotropic structure of the teleconnection pattern (P. Xu et al. 2019).

The leading mode is associated with a west-east seesaw pattern. In the positive phase, positive anomalies appear to the west of $67.5^{\circ} \mathrm{E}$ and negative ones to the east of this longitude, with the positive and negative centers near $63^{\circ} \mathrm{N}, 46.5^{\circ} \mathrm{E}$ and $60^{\circ} \mathrm{N}, 90^{\circ} \mathrm{E}$, respectively. The correlation coefficient of JJA-mean $250-\mathrm{hPa}$ meridional wind between these two centers is -0.63 , consistent with the seesaw pattern of EOF1. These anomalies correspond well to the cells of strong standard deviations shown in Fig. 1b, suggesting that the leading mode significantly contributes to the total variance of interannual variability in the upper-tropospheric meridional winds.

In this study, we define a high-latitude Eurasian teleconnection (HET) index (HETI) as the standardized difference in JJA-mean 250 -hPa meridional winds between the two centers of $\mathrm{EOF} 1$ (i.e., $63^{\circ} \mathrm{N}, 46.5^{\circ} \mathrm{E}$ minus $60^{\circ} \mathrm{N}, 90^{\circ} \mathrm{E}$ ) to quantitatively estimate the interannual variation of the HET. Therefore, the spatial pattern shown in Fig. 2a is considered to be the positive phase of the HET. The HETI is shown as the red line in Fig. $2 b$.

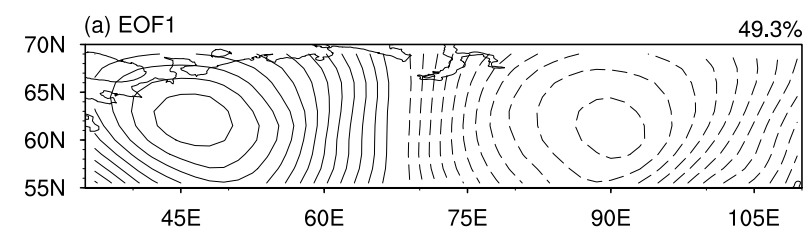

(b) PC1

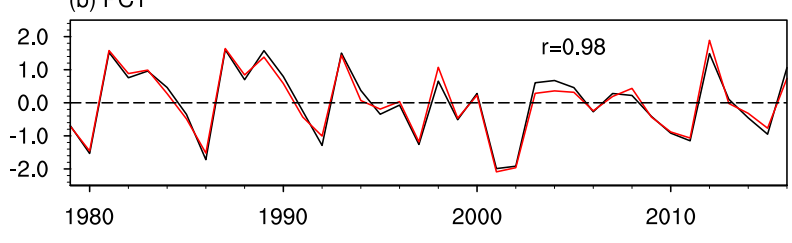

FIG. 2. (a) EOF1, the leading mode of the 250-hPa meridional wind $\left(\mathrm{m} \mathrm{s}^{-1}\right)$ within the domain $55^{\circ}-70^{\circ} \mathrm{N}, 35^{\circ}-110^{\circ} \mathrm{E}$. Zero contours are omitted. This mode explains $49.3 \%$ of the total variance. (b) Time series of the leading mode (PC1; black line) and the HET index (HETI; red line; see text for details).

The HETI is highly correlated with PC1, with the correlation coefficient being 0.98 . Despite the high correlation, we prefer to use the HETI considering its simplicity. The HETI, as well as PC1, exhibits clear interannual variation, but no distinct decadal variation.

Figure 3 shows the 250-hPa meridional wind anomalies regressed against the normalized HETI. A clear teleconnection pattern appears over the high-latitude Eurasian continent along $63^{\circ} \mathrm{N}$, with alternatively southerly and northerly anomalies. The horizontal wave activity flux (Takaya and Nakamura 2001) indicates that the HET is a stationary Rossby wave train that originates from the North Atlantic and Europe and extends eastward across the Eurasian continent. The teleconnection pattern is in good agreement with those shown by previous studies (Xie and Kosaka 2016; P. Xu et al. 2019) and resembles the pattern of 500-hPa geopotential height identified by Li and Ruan (2018), particularly over the northwest part of the Eurasian continent. The correlation coefficients between the HETI and the wave train indexes defined by Li and Ruan (2018) and P. Xu et al. (2019) are -0.60 and 0.96 , respectively. On the other hand, to test the connection between the HET and the midlatitude SRP, the SRP index (SRPI) defined by Yasui and Watanabe (2010) is employed, which is given by the standardized $\mathrm{PC} 1$ of EOF analysis on $200-\mathrm{hPa}$ meridional winds over $20^{\circ}-60^{\circ} \mathrm{N}, 0^{\circ}-150^{\circ} \mathrm{E}$. The correlation coefficient between the HETI and SRPI is only 0.10 , suggesting that these two teleconnection patterns are largely independent of each other.

In the following, we make a detailed inspection of the maintenance mechanism of the HET using the analysis procedure adopted by Kosaka et al. (2009). We focus on the baroclinic energy conversion (CP) associated with the HET. The barotropic energy conversion (CK) is not 


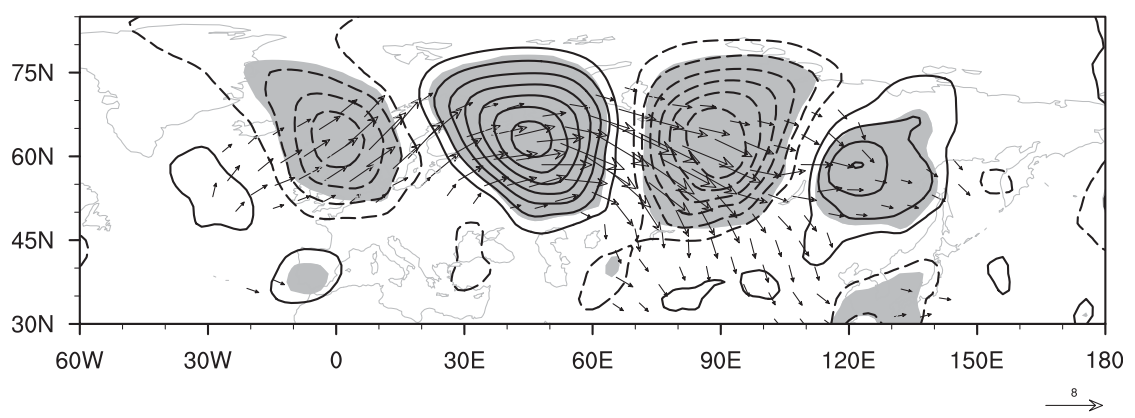

FIG. 3. The 250-hPa meridional wind anomalies (contours) regressed onto the standardized HETI and associated horizontal wave activity flux (vectors). The contour interval is $0.5 \mathrm{~m} \mathrm{~s}^{-1}$, and the zero contours are not shown. The shading denotes the $95 \%$ confidence level based on the Student's $t$ test. Vectors less than $1.5 \mathrm{~m}^{2} \mathrm{~s}^{-2}$ are omitted.

discussed here, as it is much less efficient in energy conversion (not shown), consistent with $\mathrm{P}$. $\mathrm{Xu}$ et al. (2019). The evaluation of CP is based on the following formula (e.g., Kosaka and Nakamura 2006; Kosaka et al. 2009; Hu et al. 2018; P. Xu et al. 2019):

$$
\mathrm{CP}=-\left(\frac{f}{\sigma} v^{\prime} T^{\prime} \frac{\partial \bar{u}}{\partial p}-\frac{f}{\sigma} u^{\prime} T^{\prime} \frac{\partial \bar{v}}{\partial p}\right) .
$$

Here, $u, v$, and $T$ denote the zonal wind, meridional wind, and temperature, respectively. Overbars indicate the climatological JJA mean, and primes denote the perturbations regressed onto the normalized HETI. Also, $f$ is the Coriolis parameter, $p$ is pressure, and $\sigma$ is the stability parameter $\sigma=\left(R \bar{T} / C_{p} p\right)-(d \bar{T} / d p)$, with $R$ being the gas constant and $C_{p}$ the specific heat at constant pressure. Positive $\mathrm{CP}$ means the conversion of available potential energy from the mean flow to the teleconnection pattern.

To measure the net contribution of $\mathrm{CP}$ to the maintenance of the monthly anomalies associated with the HET, we evaluate the time scales:

$$
\tau_{\mathrm{CP}}=\frac{\langle[\mathrm{APE}]\rangle}{\langle[\mathrm{CP}]\rangle},
$$

where the angle brackets $(\langle\rangle)$ represent either the area average over the Northern Hemisphere $5^{\circ}-85^{\circ} \mathrm{N}$ or the wave train domain $45^{\circ}-75^{\circ} \mathrm{N}, 30^{\circ} \mathrm{W}-150^{\circ} \mathrm{E}$ and the square brackets ([]) indicate vertical integration. $\mathrm{APE}=R T^{2} / 2 \sigma p$ is available potential energy associated with the HET; $\tau_{\mathrm{CP}}$ denotes how long it takes the observed available potential energy anomalies to be fully replenished through $\mathrm{CP}$.

Figure 4 shows the $\mathrm{CP}$ and its two terms, that is, $-(f / \sigma) v^{\prime} T^{\prime}(\partial \bar{u} / \partial p)(\operatorname{term} 1)$ and $(f / \sigma) u^{\prime} T^{\prime}(\partial \bar{v} / \partial p)($ term 2$)$, integrated from the surface to $100 \mathrm{hPa}$, associated with the HET. CP is characterized by alternatively positive and negative values over the high-latitude Eurasian continent (Fig. 4a). However, positive CP is obviously larger than negative $\mathrm{CP}$, indicating that the wave train can extract available potential energy from the mean flow to maintain or reinforce itself through baroclinic energy conversion. The available potential energy of the perturbations can be replenished within one week over the Northern Hemisphere (4.04 days), and the baroclinic energy conversion is more efficient when focused on the wave train domain (only 3.11 days). Since the conversion time scale is much shorter than one month, the HET can be easily maintained against dissipative processes.
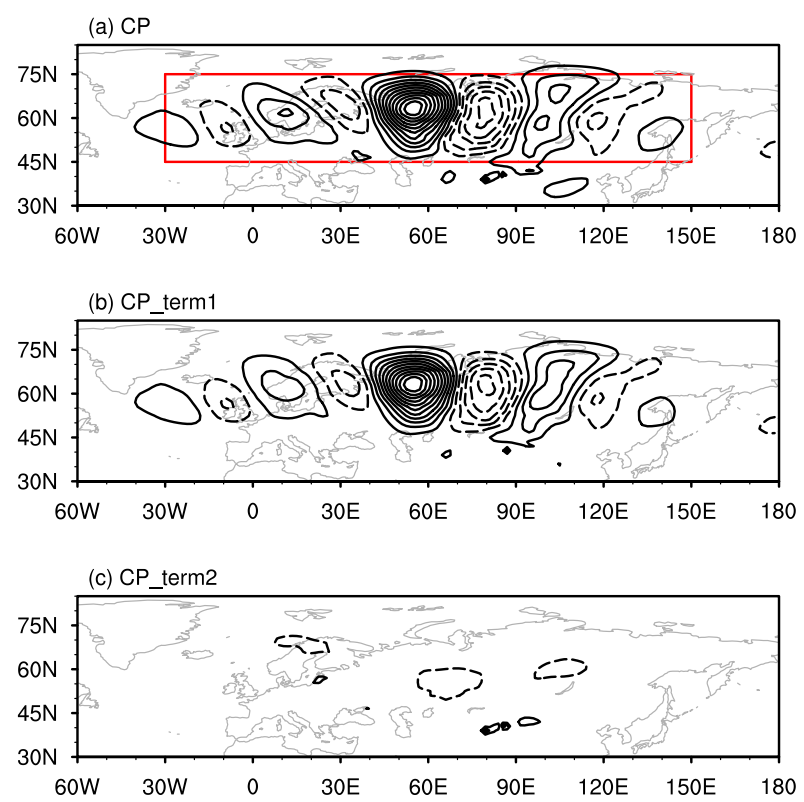

FIG. 4. (a) The vertically integrated (from surface to $100 \mathrm{hPa}$ ) baroclinic energy conversion (CP) associated with the HET. (b) The vertical integration of the first term $\left[-(f / \sigma) v^{\prime} T^{\prime}(\partial \bar{u} / \partial p)\right]$ and (c) the second term $\left[(f / \sigma) u^{\prime} T^{\prime}(\partial \bar{v} / \partial p)\right]$ of CP. The contour interval is $0.02 \mathrm{~W} \mathrm{~m}^{-2}$. Zero contours are not shown. The red box in (a) indicates the wave train domain $\left(45^{\circ}-75^{\circ} \mathrm{N}, 30^{\circ} \mathrm{W}-150^{\circ} \mathrm{E}\right)$. 


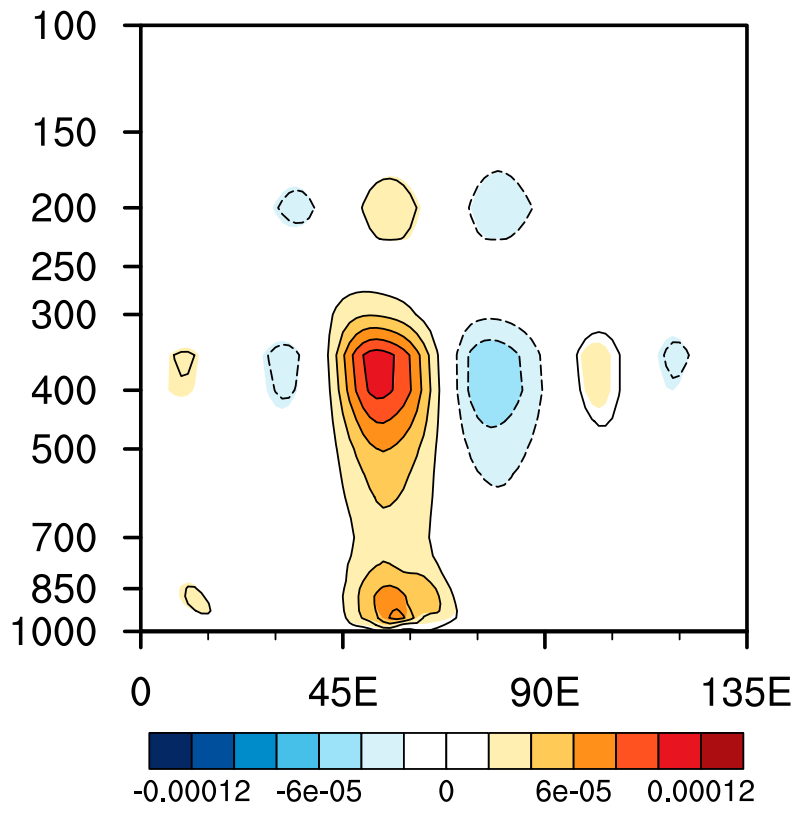

FIG. 5. The vertical section of baroclinic energy conversion CP (shadings) and its first term $\left[-(f / \sigma) v^{\prime} T^{\prime}(\partial \bar{u} / \partial p)\right.$; contours] along $63^{\circ} \mathrm{N}$. The contour interval is $2.0 \times 10^{-5} \mathrm{~m}^{2} \mathrm{~s}^{-3}$, and zero contours are omitted.

The predominant term in $\mathrm{CP}$ is $-(f / \sigma) v^{\prime} T^{\prime}(\partial \bar{u} / \partial p)$ (Fig. 4b vs Fig. 4c), and its distribution well resembles that for CP (Fig. 4a). The area-averaged value of this term is $0.0045 \mathrm{~W} \mathrm{~m}^{-2}$ over the Northern Hemisphere and $0.0207 \mathrm{~W} \mathrm{~m}^{-2}$ over the wave train domain, larger than those of the total $\mathrm{CP}\left(0.0043 \mathrm{~W} \mathrm{~m}^{-2}\right.$ over the Northern Hemisphere and $0.0186 \mathrm{~W} \mathrm{~m}^{-2}$ over the wave train domain). The other term, $(f / \sigma) u^{\prime} T^{\prime}(\partial \bar{v} / \partial p)$, on the other hand, is very weak (Fig. 4c). Therefore, we focus on the first term $\left[-(f / \sigma) v^{\prime} T^{\prime}(\partial \bar{u} / \partial p)\right]$ of $\mathrm{CP}$ in the following.

Figure 5 shows the vertical section of $\mathrm{CP}$ and $-(f / \sigma) v^{\prime} T^{\prime}(\partial \bar{u} / \partial p)$ along $63^{\circ} \mathrm{N}$, which is approximately the latitude of strongest positive and negative vertically integrated values (Figs. 4a,b). For each pressure level, $\mathrm{CP}$ is almost same as $-(f / \sigma) v^{\prime} T^{\prime}(\partial \bar{u} / \partial p)$, consistent with the integrated results (Fig. 4). Most of the baroclinic energy conversion occurs below $250 \mathrm{hPa}$, with the maximum amplitudes appearing at midtroposphere $(400 \mathrm{hPa})$. Positive CP also extends downward to the lower troposphere and shows an amplitude maximum at $925 \mathrm{hPa}$. Negative CP, on the other hand, only appears over the midtroposphere. In addition, there are also some cells above $250 \mathrm{hPa}$ but the values are very weak.

Figure 6 shows $-(f / \sigma) v^{\prime} T^{\prime}(\partial \bar{u} / \partial p)$ integrated from 700 to $300 \mathrm{hPa}$ and from 1000 to $700 \mathrm{hPa}$, to investigate baroclinic energy conversion in the midtroposphere and lower troposphere. The distributions of $-(f / \sigma) v^{\prime} T^{\prime}(\partial \bar{u} / \partial p)$ at

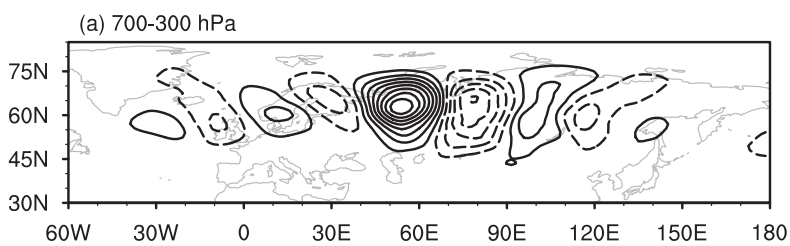

(b) $1000-700 \mathrm{hPa}$

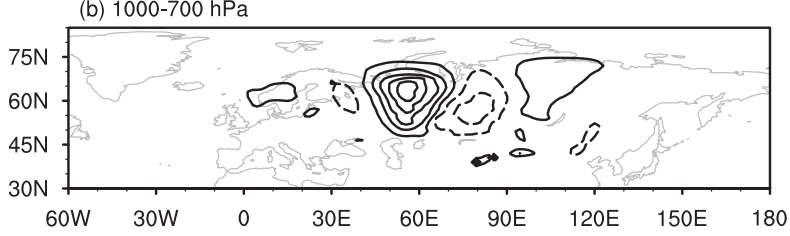

FIG. 6. Baroclinic energy conversion $\mathrm{CP}$ associated with the HET integrated over the (a) midtroposphere (700-300 hPa) and (b) lower troposphere $(1000-700 \mathrm{hPa})$. The contour interval is $0.02 \mathrm{~W} \mathrm{~m}^{-2}$. Zero contours are not shown.

the middle and lower troposphere both resemble the wavelike distribution for the whole troposphere (Fig. 4b), although both the positive and negative values in the midtroposphere appear to be larger than those in the lower troposphere. The values of $-(f / \sigma) v^{\prime} T^{\prime}(\partial \bar{u} / \partial p)$ averaged over the Northern Hemisphere and the wave train domain for the middle and lower troposphere are listed in Table 1 . The value of $-(f / \sigma) v^{\prime} T^{\prime}(\partial \bar{u} / \partial p)$ averaged over the wave train domain is $0.0106 \mathrm{~W} \mathrm{~m}^{-2}$ for the midtroposphere and $0.0100 \mathrm{~W} \mathrm{~m}^{-2}$ for the lower troposphere. Therefore, we can conclude that this term or baroclinic energy conversion in the midtroposphere and lower troposphere equivalently maintains or reinforces the HET.

Note that $-(f / \sigma) v^{\prime} T^{\prime}(\partial \bar{u} / \partial p)$ is determined by both the disturbance structure and the basic state, that is, $v^{\prime} T^{\prime}$ and $-(f / \sigma)(\partial \bar{u} / \partial p)$. Figure 7 shows the vertical cross section of these two components along $63^{\circ} \mathrm{N}$. The wavelike distribution of $v^{\prime} T^{\prime}$ resembles that of CP (Figs. 7a and 5), but with opposite-signed cells below and above $250 \mathrm{hPa}$. For those below $250 \mathrm{hPa}$, positive values are obviously greater than the negative ones, contributing to the positive CP. Positive values also extend downward to the surface, while negative values in the low levels are very weak. On the other hand, the basic state component shows two large bands in the lower troposphere and midtroposphere, respectively (Fig. 7b), consistent with the most efficient energy conversion there. In addition, $-(f / \sigma)(\partial \bar{u} / \partial p)$ is very weak above $250 \mathrm{hPa}$, leaving weak values of CP there, although $v^{\prime} T^{\prime}$ is strong (Figs. 7 and 5).

Figure 8 further looks into the vertical cross section of the disturbance term. The vertical cross section of meridional wind anomalies $v^{\prime}$ clearly exhibits an equivalentbarotropic teleconnection pattern, with maxima of anomalies at $250 \mathrm{hPa}$. These anomalies extend downward 
TABLE 1. The $-(f / \sigma) v^{\prime} T^{\prime}(\partial \bar{u} / \partial p)\left(\mathrm{W} \mathrm{m}^{-2}\right)$ averaged over the Northern Hemisphere $\left(\mathrm{NH} ; 5^{\circ}-85^{\circ} \mathrm{N}\right)$ and the wave train domain (WTD; $\left.45^{\circ}-75^{\circ} \mathrm{N}, 30^{\circ} \mathrm{W}-150^{\circ} \mathrm{E}\right)$. The values have been integrated in the midtroposphere $(700-300 \mathrm{hPa})$ and lower troposphere $(1000-700 \mathrm{hPa})$, respectively.

\begin{tabular}{lcc}
\hline \hline & NH & WTD \\
\hline $700-300 \mathrm{hPa}$ & 0.0023 & 0.0106 \\
$1000-700 \mathrm{hPa}$ & 0.0021 & 0.0100 \\
\hline
\end{tabular}

to the surface, except over Northeast Asia, where the anomalies are weak at the low level possibly due to the topography. Similar to the results for $250 \mathrm{hPa}$, the strongest positive and negative meridional wind anomalies for each level appear at about $45^{\circ}$ and $90^{\circ} \mathrm{E}$, respectively. However, these positive anomalies tilt westward with height, while the negative ones tilt slightly eastward in the troposphere. The temperature anomalies $T^{\prime}$ also exhibit equivalent-barotropic features, showing anomalous centers in the upper and lower troposphere, respectively. Note that $T^{\prime}$ exhibits opposite-signed anomalies below and above $250 \mathrm{hPa}$, resulting in opposite-signed $v^{\prime} T^{\prime}$ below and above this level (Fig. 7a). In the troposphere, the positive $T^{\prime}$ between $45^{\circ}$ and $90^{\circ} \mathrm{E}$ is strongest and extends clearly to the surface. This temperature anomaly is well associated with the anticyclonic anomaly indicated by the positive and negative meridional wind anomalies. However, a closer inspection indicates that $v^{\prime}$ leads $T^{\prime}$ not exactly by $1 / 4$ phase in the troposphere, especially in the lower levels, leading to nonzero values for $v^{\prime} T^{\prime}$, an issue discussed further in the next section.

Figure 9 shows the vertical cross section of the components associated with the basic state $[-(f / \sigma)(\partial \bar{u} / \partial p)]$ along $63^{\circ} \mathrm{N}$. The term $f / \sigma$ shows its largest values in the lower troposphere (Fig. 9a), which results from smallest values of $\sigma$, suggesting that the atmospheric stratification is more unstable in the lower troposphere. The distribution of $f / \sigma$ corresponds well to the distribution of land and sea in the lower troposphere. There are larger values over the Eurasian continent $\left(0^{\circ}-150^{\circ} \mathrm{E}\right)$ and North America $\left(165^{\circ}-95^{\circ} \mathrm{W}\right)$, but smaller values over the North Pacific $\left(150^{\circ} \mathrm{E}-165^{\circ} \mathrm{W}\right)$ and North Atlantic $\left(95^{\circ} \mathrm{W}-0^{\circ}\right)$. This is because land warms up faster than the ocean during summer and the temperature in the lower troposphere is easily affected by the surface sensible heat flux. Therefore, the atmospheric stratification over land is more unstable than that over the ocean. Also, $f / \sigma$ is relatively large and uniform in the midtroposphere around $400 \mathrm{hPa}$, consistent with large $\mathrm{CP}$ there. The two large bands of $f / \sigma$ correspond well to those of the basic state (Fig. $7 b$ ), indicating that $f / \sigma$ plays an important role in the basic state component. In addition, $f / \sigma$ becomes very weak above $250 \mathrm{hPa}$, due to the strong stability of atmosphere in the stratosphere. As a result, $-(f / \sigma) v^{\prime} T^{\prime}(\partial \bar{u} / \partial p)$ and $\mathrm{CP}$ are very weak there (Fig. 5).

The term $\sigma$ is determined by two components: $R \bar{T} / C_{p} p$ and $\partial \bar{T} / \partial p$. As the air density decreases with height, the term $R \bar{T} / C_{p} p$ expectedly increases, and exhibits nearly uniform values at each level (Fig. 9b). Even for the lower troposphere, where the temperature and pressure may depend appreciably on the distribution of land and sea, this term is almost constant in the zonal direction. For instance, the $R \bar{T} / C_{p} p$ values are very similar over the Eurasian continent and North Pacific at $925 \mathrm{hPa}$, being $8.80 \times 10^{-4}$ and $8.70 \times 10^{-4} \mathrm{~K} \mathrm{~Pa}^{-1}$ averaged over $63^{\circ} \mathrm{N}, 0^{\circ}-150^{\circ} \mathrm{E}$ and $63^{\circ} \mathrm{N}, 150^{\circ} \mathrm{E}-165^{\circ} \mathrm{W}$, respectively. Therefore, this term can contribute to smallest values of $\sigma$ in the lower

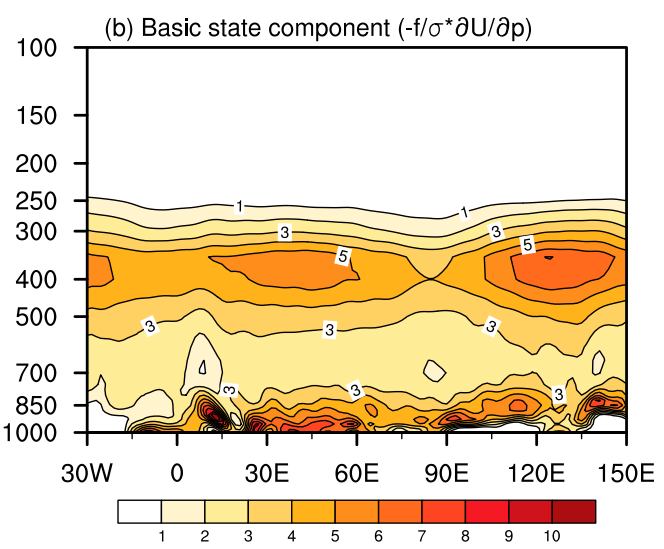

FIG. 7. The vertical section of (a) the disturbance component $\left(v^{\prime} T^{\prime} ; \mathrm{m} \mathrm{K} \mathrm{s}^{-1}\right)$ and (b) the basic state component $\left[-(f / \sigma)(\partial \bar{u} / \partial p) ; 1.0 \times 10^{-5} \mathrm{~m} \mathrm{~K}^{-1} \mathrm{~s}^{-2}\right]$ associated with $-(f / \sigma) v^{\prime} T^{\prime}(\partial \bar{u} / \partial p)$ along $63^{\circ} \mathrm{N}$. The contour intervals in (a) and (b) are 0.5 and 1.0, respectively. Zero contours are omitted in (a). 


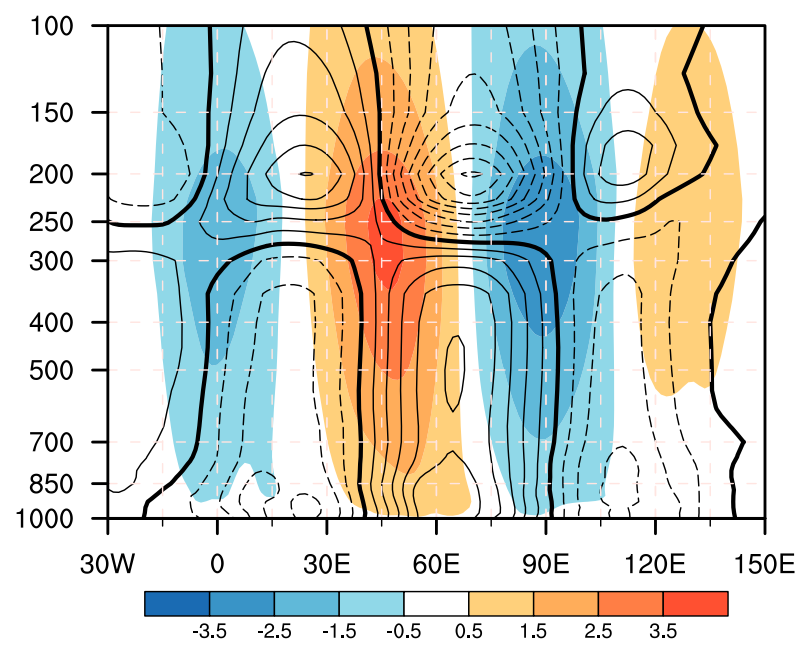

FIG. 8. The vertical section of meridional wind anomalies $v^{\prime}$ (shading; $\mathrm{m} \mathrm{s}^{-1}$ ) and temperature anomalies $T^{\prime}$ (black contours) regressed onto the normalized HETI along $63^{\circ} \mathrm{N}$. The contour interval is $0.2 \mathrm{~K}$, and zero contours are in bold.

troposphere, but cannot explain the distinct land-sea distribution of $\sigma$.

The term $\partial \bar{T} / \partial p$ basically increases with height in the troposphere and shows its largest values in the middle to upper levels (Fig. 9c). These large values, together with $R \bar{T} / C_{p} p$, which increases with height (Fig. 9b), lead to relatively weaker $\sigma$ and resultant greater $f / \sigma$ around $400 \mathrm{hPa}$ (Fig. 9a). In the lower troposphere, on the other hand, the term $\partial \bar{T} / \partial p$ shows a distinct land-sea distribution, being larger over the continents than the oceans. For example, the difference in climatological mean temperature between 1000 and $850 \mathrm{hPa}$ averaged over the Eurasian continent at $63^{\circ} \mathrm{N}, 0^{\circ}-150^{\circ} \mathrm{E}$ is $8.95 \mathrm{~K}, 76 \%$ larger than that over the North Atlantic at $63^{\circ} \mathrm{N}$, $95^{\circ} \mathrm{W}-0^{\circ}(5.09 \mathrm{~K})$. This term is associated with the basic state of temperature, which decreases with height, as expected (Fig. 9d). The basic state of temperature in the lower troposphere also exhibits a distinct land-sea contrast, with higher temperature over the continents than the oceans. These features favor lower stability of the atmospheric stratification over the continents.

On the other hand, the climatological zonal winds increase uniformly with height below $250 \mathrm{hPa}$ and decrease above this level (Fig. 9f), and thus the term $-\partial \bar{u} / \partial p$ is almost a constant below $250 \mathrm{hPa}$ (Fig. 9e), with a value of around $1.0 \times 10^{-4} \mathrm{~m} \mathrm{~Pa}^{-1} \mathrm{~s}^{-1}$. This result indicates that the basic flow in the high latitudes shows not only weak zonal and meridional shear (Fig. 1a), but also weak vertical shear (Fig. 9e). This is distinctly different from the basic flow in the midlatitudes, where $-\partial \bar{u} / \partial p$ shows very strong values below and above the westerly jet. Therefore, compared to $-\partial \bar{u} / \partial p$, the atmospheric stability $\sigma$ plays a more important role in the basic state component of CP (Figs. 9a and 9e vs Fig. 7b).

The results in this section indicate that the HET can be maintained by extracting available potential energy from the basic flow (i.e., the baroclinic energy conversion, CP). CP is efficient not only in the midtroposphere, but also in the lower troposphere. The perturbations associated with the HET and the basic state both significantly contribute to positive CP. Especially, the atmospheric stability associated with the basic state of temperature in the lower troposphere is important. This is distinctly different from the midlatitude teleconnection, which greatly relies on the basic state of the zonal wind in the middle to upper levels. The results in this section are obtained by the vertical cross section of these components. The horizontal distribution of these components in the midtroposphere and lower troposphere is investigated further in the subsequent section.

\section{Baroclinic energy conversion $C P$ associated with the HET in the midtroposphere and lower troposphere}

The results in the preceding section indicate that the $\mathrm{CP}$ associated with the HET features two maxima in amplitude at 400 and $925 \mathrm{hPa}$, respectively. In this section, we further explore the horizontal distribution of baroclinic energy conversion at these two levels.

Figure 10 shows the distributions of $-(f / \sigma) v^{\prime} T^{\prime}(\partial \bar{u} / \partial p)$ and each component associated with this term at $400 \mathrm{hPa}$. The term $-(f / \sigma) v^{\prime} T^{\prime}(\partial \bar{u} / \partial p)$ exhibits alternating positive and negative values (Fig. 10a). The positive values are obviously larger than the negative ones. The maximum positive value (at $63^{\circ} \mathrm{N}, 52.5^{\circ} \mathrm{E}$ ) is $1.07 \times$ $10^{-4} \mathrm{~W} \mathrm{~m}^{-2}, 70 \%$ higher than the maximum negative value (at $64.5^{\circ} \mathrm{N}, 78^{\circ} \mathrm{E} ;-6.13 \times 10^{-5} \mathrm{~W} \mathrm{~m}^{-2}$ ). The higher positive values are dominated by the larger positive values of the disturbance term $v^{\prime} T^{\prime}$ (Fig. 10c), the distribution of which resembles $-(f / \sigma) v^{\prime} T^{\prime}(\partial \bar{u} / \partial p)$. The term $v^{\prime} T^{\prime}$ at $63^{\circ} \mathrm{N}, 52.5^{\circ} \mathrm{E}$ is $2.00 \mathrm{~m} \mathrm{~K} \mathrm{~s}^{-1}, 50 \%$ higher than that at $64.5^{\circ} \mathrm{N}, 78^{\circ} \mathrm{E}\left(-1.33 \mathrm{~m} \mathrm{~K} \mathrm{~s}^{-1}\right)$. The pattern of $v^{\prime} T^{\prime}$ is associated with the configuration of $v^{\prime}$ and $T^{\prime}$. It is found that $v^{\prime}$ leads $T^{\prime}$ roughly by $1 / 4$ phase (Figs. $10 \mathrm{e}$ and $12 \mathrm{a}$ ), which can be explained by the association between the anticyclonic (cyclonic) anomaly and warmer (cooler) temperatures. However, a careful scrutiny shows that the center of positive $v^{\prime}$ appears over positive $T^{\prime}$, rather than at the zero contour (Fig. 12a). The configuration of $v^{\prime}$ and $T^{\prime}$ is important for the sign of $v^{\prime} T^{\prime}$ : The total sum of $v^{\prime} T^{\prime}$ is positive (negative) if $v^{\prime}$ leads or lags $T^{\prime}$ by less (more) than $1 / 4$ phase, and it is zero if $v^{\prime}$ leads or lags $T^{\prime}$ exactly by $1 / 4$ phase. Therefore, although $v^{\prime} T^{\prime}$ shows alternative positive and negative values, the 
(a) $f / \sigma$

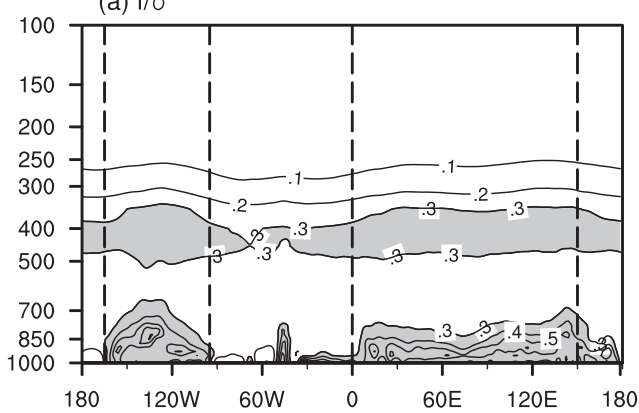

(c) $\partial \mathrm{T} / \partial \mathrm{P}$

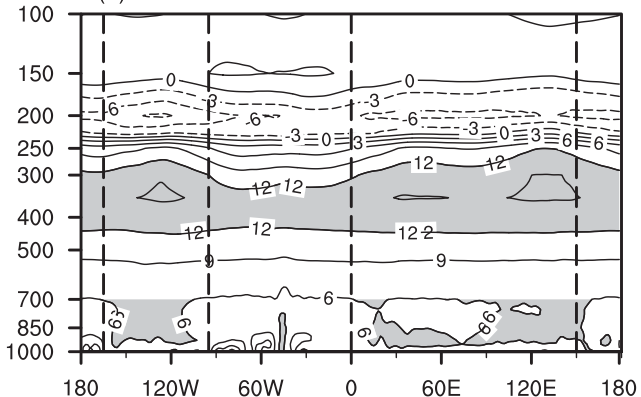

(e) $-\partial \mathrm{U} / \partial \mathrm{p}$

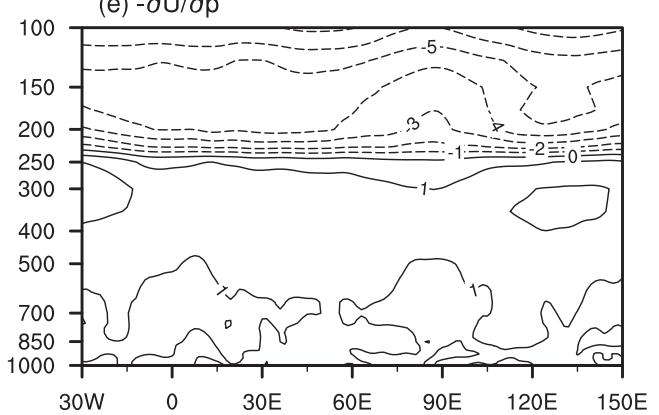

(b) $R T / C_{p} p$

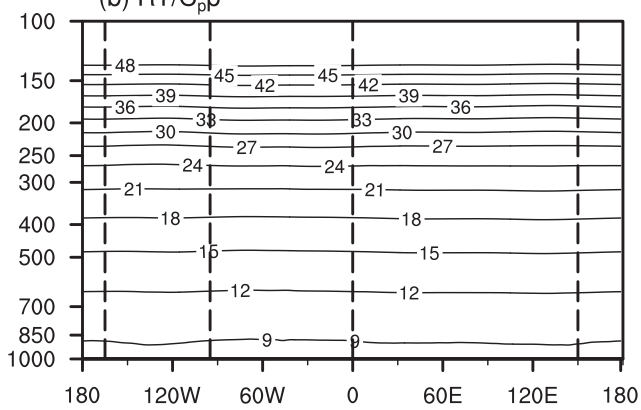

(d) $\mathrm{T}$

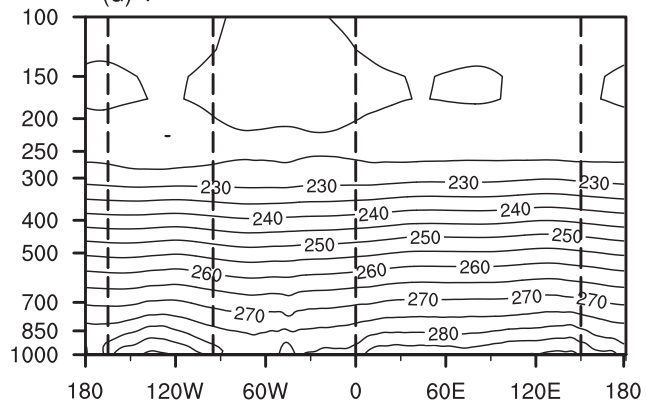

(f) $U$

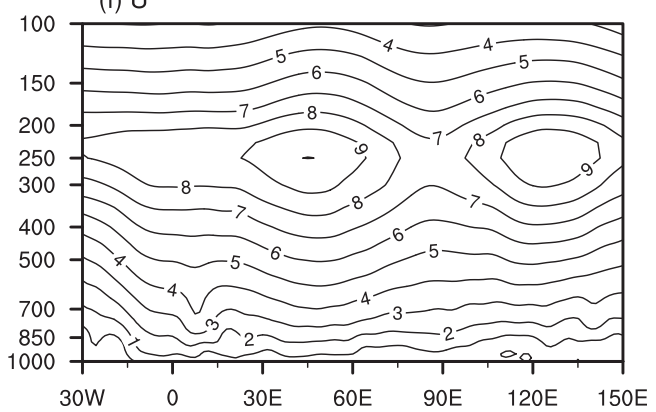

FIG. 9. (a) The vertical section of terms associated with the basic state: (a) $f / \sigma\left(\mathrm{Pa} \mathrm{K}^{-1} \mathrm{~s}^{-1}\right)$, (b) $R \bar{T} / C_{p} p(1.0 \times$ $\left.10^{-4} \mathrm{~K} \mathrm{~Pa}^{-1}\right)$, (c) $\partial \bar{T} / \partial p\left(1.0 \times 10^{-4} \mathrm{~K} \mathrm{~Pa}^{-1}\right)$, (d) the climatological mean of temperature $(\mathrm{K}),(\mathrm{e})-\partial \bar{u} / \partial p(1.0 \times$ $\left.10^{-4} \mathrm{~m} \mathrm{~Pa}^{-1} \mathrm{~s}^{-1}\right)$, and (f) the climatological mean of zonal wind $\left(\mathrm{m} \mathrm{s}^{-1}\right)$, along $63^{\circ} \mathrm{N}$. The contour intervals in (a), (b), (d), (e), and (f) are 0.1, 3.0, 5.0,1.0, and 1.0, respectively. Values greater than 0.3 in (a) are shaded. Shading in (c) indicates values greater than 12.0 and those greater than 6.0 in the lower troposphere $(1000-700 \mathrm{hPa})$. The dashed lines in (a)-(d) are $165^{\circ} \mathrm{W}, 95^{\circ} \mathrm{W}, 0^{\circ}$, and $150^{\circ} \mathrm{E}$, respectively.

positive ones are stronger than the negative ones (Fig. 10c).

On the other hand, the term associated with the basic state $[-(f / \sigma)(\partial \bar{u} / \partial p)]$ is strongest over midlatitude Eurasia and the North Atlantic, and shows another relatively high-amplitude belt over high-latitude Eurasia (Fig. 10b). For the midlatitude Eurasia and North Atlantic, the basic state of zonal wind $(-\partial \bar{u} / \partial p)$ plays a dominant role due to the existence of the westerly jet (Figs. 10b,d). However, over high-latitude Eurasia $-\partial \bar{u} / \partial p$ is much smaller. By contrast, the stability parameter $\sigma$ is smaller over high-latitude Eurasia (Fig. 10f) than in the midlatitudes. Besides, the Coriolis parameter $f$ over the high latitudes is larger than that in the midlatitudes, which is $12.99 \times 10^{-5} \mathrm{~s}^{-1}$ for $63^{\circ} \mathrm{N}$ and $9.37 \times$ $10^{-5} \mathrm{~s}^{-1}$ for $40^{\circ} \mathrm{N}$. As a result, $f / \sigma$ in the high latitudes is larger than that in the midlatitudes. Therefore, $f / \sigma$ is important for the energy conversion in the high latitudes, while for the midlatitudes the energy conversion is more favored by the basic state of zonal wind.

Figure 11 shows the distributions of $-(f / \sigma) v^{\prime} T^{\prime}(\partial \bar{u} / \partial p)$ and each component associated with this term at $925 \mathrm{hPa}$. Positive $-(f / \sigma) v^{\prime} T^{\prime}(\partial \bar{u} / \partial p)$ mainly appears over $50^{\circ}-72.5^{\circ} \mathrm{N}, 40^{\circ}-70^{\circ} \mathrm{E}$, indicating that baroclinic energy conversion is most efficient there (Fig. 11a). Notably, $-(f / \sigma) v^{\prime} T^{\prime}(\partial \bar{u} / \partial p)$ over the other regions is very weak. 

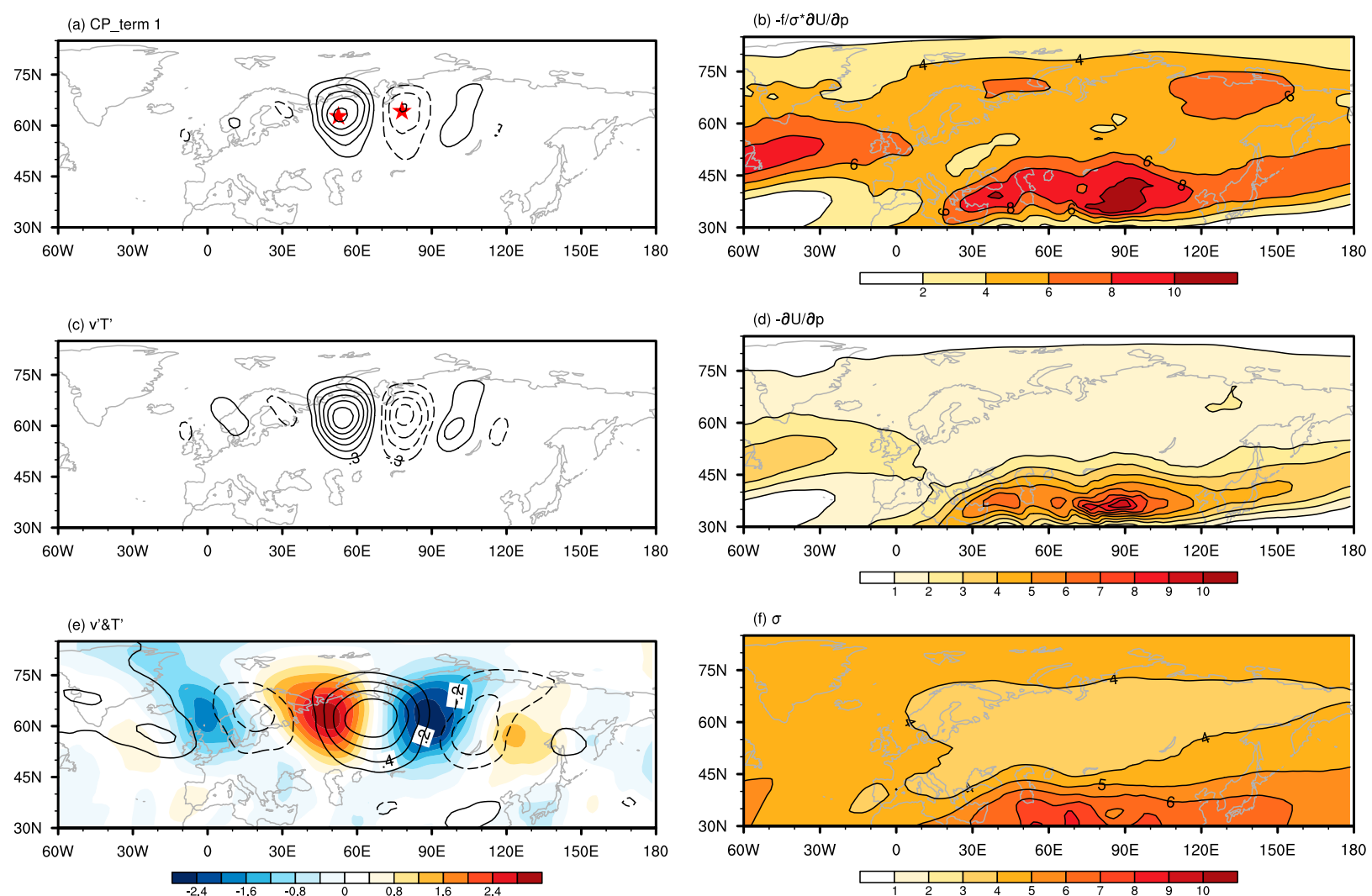

FIG. 10. (a) The first term of CP $\left[-(f / \sigma) v^{\prime} T^{\prime}(\partial \bar{u} / \partial p) ; 1.0 \times 10^{-5} \mathrm{~m}^{2} \mathrm{~s}^{-3}\right]$ and the terms associated with (c),(e) disturbance and (b),(d),(f) basic state: $-(f / \sigma)(\partial \bar{u} / \partial p)\left(1.0 \times 10^{-5} \mathrm{~m} \mathrm{~K}^{-1} \mathrm{~s}^{-2}\right)$ is shown in $(\mathrm{b}), v^{\prime} T^{\prime}\left(\mathrm{m} \mathrm{K} \mathrm{s}^{-1}\right)$ in $(\mathrm{c}),-\partial \bar{u} / \partial p\left(1.0 \times 10^{-4} \mathrm{~m} \mathrm{~Pa}^{-1} \mathrm{~s}^{-1}\right)$ in $(\mathrm{d}), v^{\prime}(\mathrm{shading}$; $\mathrm{m} \mathrm{s}^{-1}$ ) and $T^{\prime}$ (black contours; $\left.\mathrm{K}\right)$ in (e), and $\sigma\left(1.0 \times 10^{-4} \mathrm{~K} \mathrm{~Pa}^{-1}\right)$ in (f), at $400 \mathrm{hPa}$. The contour intervals in (a)-(f) are 2.0, 2.0, 0.3, 1.0, 0.2 , and 0.1 , respectively. Zero contours are not shown. The red stars in (a) indicate the positions of the largest positive (at $63^{\circ} \mathrm{N}, 52.5^{\circ} \mathrm{E}$ ) and negative (at $64.5^{\circ} \mathrm{N}, 78^{\circ} \mathrm{E}$ ) value, respectively.

The distribution of $v^{\prime} T^{\prime}$ resembles $-(f / \sigma) v^{\prime} T^{\prime}(\partial \bar{u} / \partial p)$ (Fig. 11c), confirming its important role in in determining the pattern of CP. Positive $v^{\prime} T^{\prime}$ results from the strong positive $v^{\prime}$ and positive $T^{\prime}$ there (Fig. 11e). Compared to $400 \mathrm{hPa}, v^{\prime}$ and $T^{\prime}$ are more in phase at $925 \mathrm{hPa}$ (Figs. 11e and 12b); that is, the anomalous southerly flow basically corresponds to positive temperature anomalies and the anomalous northerly flow corresponds to the negative temperature anomalies. This is because the meridional gradient of mean temperature in the lower troposphere is larger than that in the midtroposphere: the value averaged over the wave train domain is $-2.02 \times 10^{-6} \mathrm{~K} \mathrm{~m}^{-1}$ at $925 \mathrm{hPa}$, stronger than that at $400 \mathrm{hPa}\left(-1.31 \times 10^{-6} \mathrm{~K} \mathrm{~m}^{-1}\right)$, and thus the temperature anomalies in the lower troposphere are greatly affected by the anomalous meridional advection of mean temperature.

The basic state term $[-(f / \sigma)(\partial \bar{u} / \partial p)]$ at this level shows a distinct land-sea distribution, with greater values over the continents than the oceans (Fig. 11b). This is mainly induced by the distinct land-sea contrast of $\sigma$ (Figs. 11b,f). For the Eurasian continent, the distribution of $-(f / \sigma)(\partial \bar{u} / \partial p)$ resembles $\sigma$ (Fig. 11f), suggesting that $\sigma$ significantly contributes to $-(f / \sigma)(\partial \bar{u} / \partial p)$. Also, $-\partial \bar{u} / \partial p$ is stronger over the high latitudes than the midlatitudes in the Eurasian continent (Fig. 11d), possibly due to the thermal contrast between the Eurasian continent and Arctic Sea through thermal wind relationship. In addition, compared to that at $400 \mathrm{hPa}$ (Fig. 10f), $\sigma$ at $925 \mathrm{hPa}$ is much weaker, suggesting that it plays a more important role in $-(f / \sigma)(\partial \bar{u} / \partial p)$ (Fig. 11f). This is because the atmosphere in the low levels is more easily affected by surface sensible heating, resulting in lower atmospheric stability. Therefore, we can confirm that the lower-tropospheric atmospheric stability plays an important role in energy conversion, which was shown in the preceding section.

It is notable that the reanalysis data are artificial under the surface. Fortunately, positive $-(f / \sigma) v^{\prime} T^{\prime}(\partial \bar{u} / \partial p)$ at $925 \mathrm{hPa}$ appears over the plains (Fig. 11a) and the reanalysis data there should be reliable. We also used the 

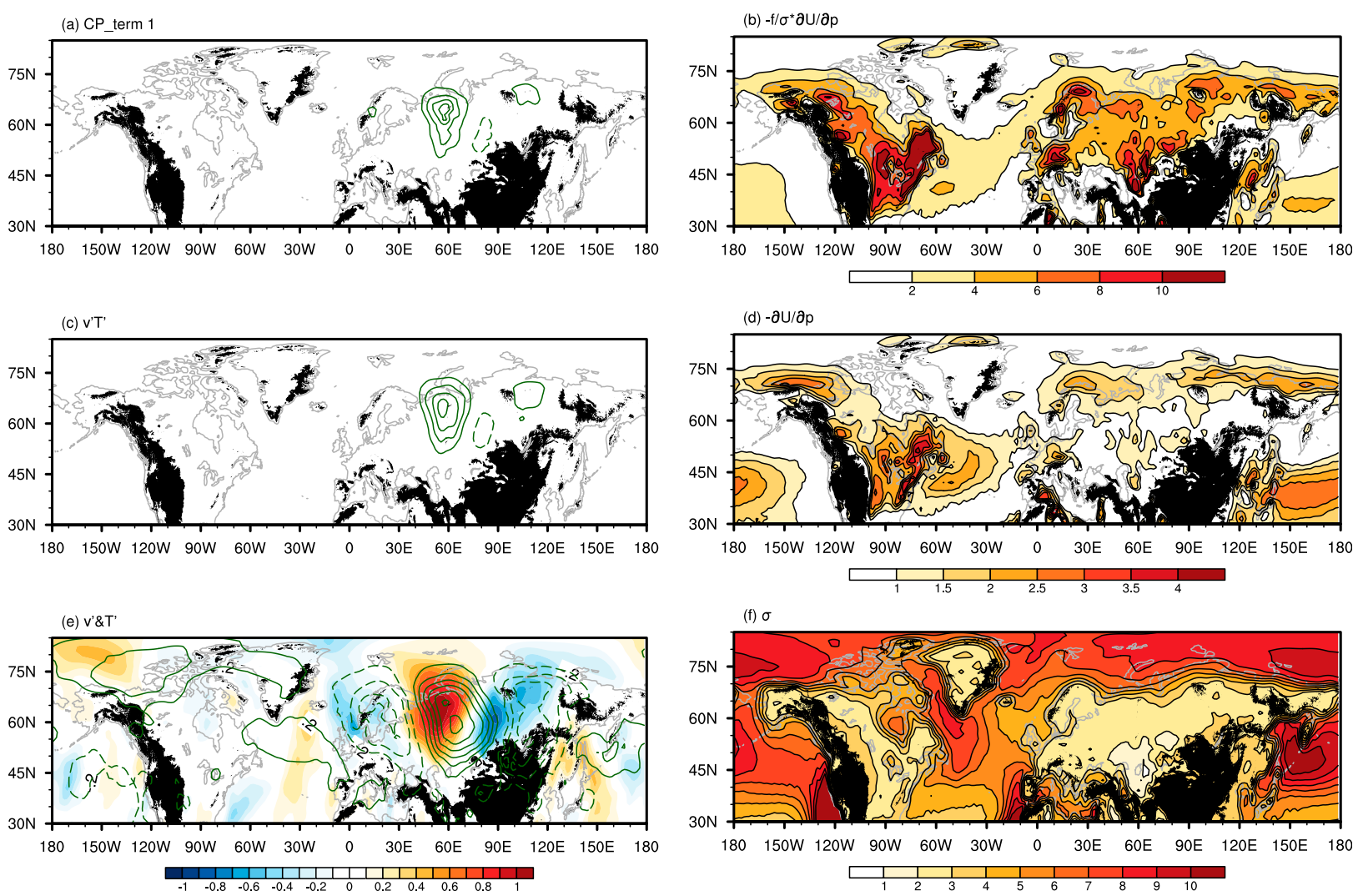

FIG. 11. (a) (a) The first term of CP $\left[-(f / \sigma) v^{\prime} T^{\prime}(\partial \bar{u} / \partial p) ; 1.0 \times 10^{-5} \mathrm{~m}^{2} \mathrm{~s}^{-3}\right]$ and the terms associated with (c),(e) disturbance and (b),(d),(f) basic state: $-(f / \sigma)(\partial \bar{u} / \partial p)\left(1.0 \times 10^{-5} \mathrm{~m} \mathrm{~K}^{-1} \mathrm{~s}^{-2}\right)$ is shown in (b), $v^{\prime} T^{\prime}\left(\mathrm{m} \mathrm{K} \mathrm{s}^{-1}\right)$ in (c), $-\partial \bar{u} / \partial p\left(1.0 \times 10^{-4} \mathrm{~m} \mathrm{~Pa}^{-1} \mathrm{~s}^{-1}\right)$ in $(\mathrm{d}), v^{\prime}$ (shading; $\mathrm{m} \mathrm{s}^{-1}$ ) and $T^{\prime}$ (black contours; $\left.\mathrm{K}\right)$ in (e), and $\sigma\left(1.0 \times 10^{-4} \mathrm{~K} \mathrm{~Pa}^{-1}\right)$ in (f), at $925 \mathrm{hPa}$. The contour intervals in (a)-(f) are 2.0, 2.0, $0.3,0.5,0.2$ and 0.1 , respectively. Zero contours are not shown. The black shading represents mountains higher than $800 \mathrm{~m}$.

NCEP-NCAR reanalysis data and the JRA-55 data to repeat these analyses and obtained similar results.

In summary, the results in this section confirm that the configuration of $v^{\prime}$ and $T^{\prime}$ plays an important role in energy conversion associated with the high-latitude teleconnection pattern. Particularly, in the lower troposphere, $v^{\prime}$ and $T^{\prime}$ are more in phase due to the larger meridional gradient of mean temperature. In addition, the basic state plays a key role in the baroclinic energy conversion for both the midtroposphere and lower troposphere. On the one hand, the stability parameter is small and the Coriolis parameter is large in the high latitudes, favoring strong baroclinic energy conversion. Especially, in the lower troposphere, the stability parameter exhibits a clear land-sea contrast, with smaller values over the continents than the oceans. On the other hand, although the vertical shear of the mean zonal wind is weak in both the middle and lower troposphere over high-latitude Eurasia, in the low levels it is relatively larger in the high latitudes than the midlatitudes. All these features determine that the lower-tropospheric energy conversion occurs in the high latitudes of the Eurasian continent.

\section{Conclusions and discussion}

In this study, we confirmed the existence of a teleconnection pattern over the high-latitude Eurasian continent in summer, and confirmed, using the same analysis procedure as Kosaka et al. (2009), that this teleconnection pattern can be maintained through baroclinic energy conversion, as has been suggested in previous studies (Xie and Kosaka 2016; P. Xu et al. 2019). We called this teleconnection pattern the high-latitude Eurasian teleconnection (HET) to emphasize the unique role of the basic state over the high latitudes of the Eurasian continent in maintaining the teleconnection, which is also the main focus of this study.

It is found that the baroclinic energy conversion is most efficient in the middle and lower troposphere. The baroclinic energy conversion in these two layers contributes equivalently to the maintenance of the HET. Further analysis indicates that baroclinic energy conversion is 
(a) $400 \mathrm{hPa}$

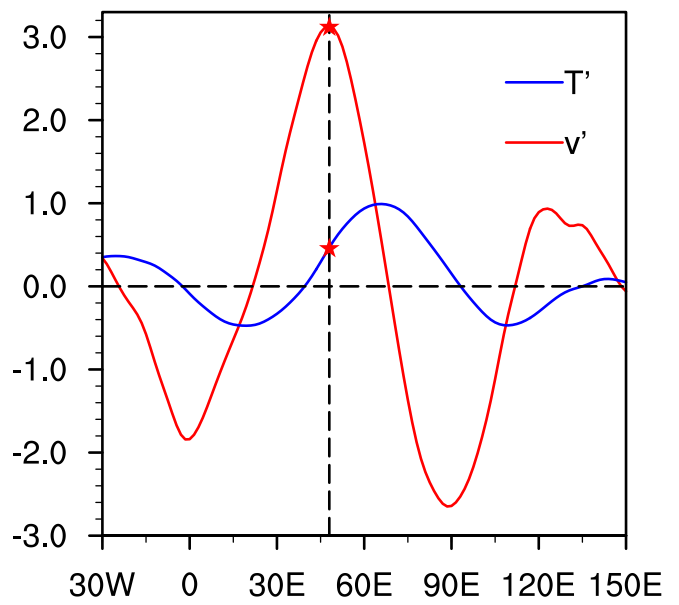

(b) $925 \mathrm{hPa}$

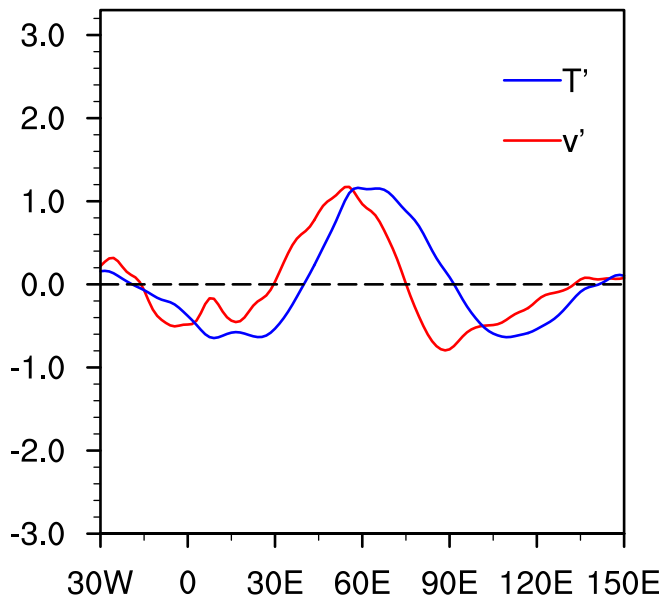

FIG. 12. The temperature anomalies $T^{\prime}(\mathrm{K})$ and meridional wind anomalies $v^{\prime}\left(\mathrm{m} \mathrm{s}^{-1}\right)$ regressed onto the normalized HETI along $63^{\circ} \mathrm{N}$ at (a) 400 and (b) $925 \mathrm{hPa}$. The vertically dashed line in (a) indicates the longitude where $v^{\prime}$ peaks, and the red stars indicate the corresponding values of $v^{\prime}$ and $T^{\prime}$, respectively.

dominated by the stability parameter and vertical gradient of zonal winds. The stability parameter is small in both the middle and lower troposphere over the high latitudes of the Eurasian continent, favoring baroclinic energy conversion. On the other hand, the vertical gradient of zonal winds is uniform in the entire troposphere over the high latitudes of the Eurasian continent. However, the vertical gradient of zonal winds is relatively larger around the northern edge of the Eurasian continent in the lower troposphere, resulting in the strong baroclinic energy conversion, together with the stability parameter. Furthermore, the disturbances associated with the HET also favor baroclinic energy conversion, by showing positive values of $v^{\prime} T^{\prime}$ larger than the negative ones. In the lower troposphere, particularly, positive values of $v^{\prime} T^{\prime}$ are much larger than the negative ones, and this is very important for baroclinic energy conversion. Finally, the Coriolis parameter, which is larger in the high latitudes, also contributes to the strong baroclinic energy conversion in the high latitudes of the Eurasian continent, as expected.

The present results indicate that the basic state plays a key role in maintaining the HET. The role of the basic state can be summarized as follows. First, the low stability in the midtroposphere over high-latitude Eurasia makes the baroclinic energy conversion there comparable to, albeit weaker than, the conversion in the midlatitudes, despite the very strong gradient of zonal winds in the latter region (Fig. 10). Second, in the lower troposphere, the stability is also low over the Eurasian continent due to surface sensible heating, and the vertical gradient of zonal winds is relatively larger over highlatitude Eurasia possibly due to the thermal contrast between the Eurasian continent and Arctic Sea during summer, both favoring strong baroclinic energy conversion (Fig. 11). Finally, the strong contrast between warm lands and cool seas around the northern edge of the Eurasian continent during summer provides a good condition for inducing the structure of disturbances that favors strong positive baroclinic energy conversion, that is, southerly (northerly) anomalies resulting in warmer (cooler) air temperatures (Fig. 11).

Considering the important role of the basic state, we speculate that the high latitudes of the Eurasian continent could be a unique region for pure high-latitude teleconnections. On the one hand, although the basic state can also favor baroclinic energy conversion over the high latitudes of North America (Fig. 11b), the longitudinal scope is much smaller and thus it prevents the appearance of teleconnections there. On the other hand, in the Southern Hemisphere during the boreal summer, we found that teleconnection patterns exist over the high latitudes (not shown), possibly favored by baroclinic energy conversion roughly around $60^{\circ} \mathrm{S}$. However, these high-latitude teleconnections are closely related to those along the upper-tropospheric westerly jet in the Southern Hemisphere, unlike the independence of mid- and high-latitude teleconnections shown in the present results. We attribute this difference between the Northern and Southern Hemisphere to the relatively poleward location of the Southern Hemisphere jet. For instance, for the austral summer, Lin (2019) identified a stationary teleconnection in the South Atlantic and south Indian Ocean (roughly around $50^{\circ} \mathrm{S}$ ) and attributed it to the strong Southern Hemisphere westerly jet there. Therefore, the mechanism for 
the teleconnection patterns in the Southern Hemisphere might be more complicated and require further investigation. In addition, this study indicates that the HET is relatively independent of the midlatitude SRP. Therefore, it could be expected that different configurations of the HET and SRP would result in different climate effects over Eurasia, which is another interesting topic for future study.

Acknowledgments. We thank Dr. Hisashi Nakamura and two anonymous reviewers for their valuable comments. This work was supported by the National Natural Science Foundation of China (Grant 41721004), the Natural Science Foundation of Jiangsu Province (BK20190500), and the Fundamental Research Funds for the Central Universities (2018B06814).

\section{REFERENCES}

Ambrizzi, T., B. J. Hoskins, and H.-H. Hsu, 1995: Rossby wave propagation and teleconnection patterns in the austral winter. J. Atmos. Sci., 52, 3661-3672, https://doi.org/10.1175/15200469(1995)052<3661:RWPATP > 2.0.CO;2.

Bladé, I., B. Liebmann, D. Fortuny, and G. J. van Oldenborgh, 2012: Observed and simulated impacts of the summer NAO in Europe: Implications for projected drying in the Mediterranean region. Climate Dyn., 39, 709-727, https://doi.org/ 10.1007/s00382-011-1195-x.

Branstator, G., and H. Teng, 2017: Tropospheric waveguide teleconnections and their seasonality. J. Atmos. Sci., $\mathbf{7 4}$, 1513-1532, https://doi.org/10.1175/JAS-D-16-0305.1.

Cassou, C., L. Terray, and A. S. Phillips, 2005: Tropical Atlantic influence on European heat waves. J. Climate, 18, 2805-2811, https://doi.org/10.1175/JCLI3506.1.

Chen, G., and R. Huang, 2012: Excitation mechanisms of the teleconnection patterns affecting the July precipitation in northwest China. J. Climate, 25, 7834-7851, https://doi.org/ 10.1175/JCLI-D-11-00684.1.

Dee, D. P., and Coauthors, 2011: The ERA-Interim reanalysis: Configuration and performance of the data assimilation system. Quart. J. Roy. Meteor. Soc., 137, 553-597, https://doi.org/ 10.1002/qj.828.

Ding, Q., and B. Wang, 2005: Circumglobal teleconnection in the Northern Hemisphere summer. J. Climate, 18, 3483-3505, https://doi.org/10.1175/JCLI3473.1.

,$- \ldots$, J. M. Wallace, and G. Branstator, 2011: Tropicalextratropical teleconnections in boreal summer: Observed interannual variability. J. Climate, 24, 1878-1896, https:// doi.org/10.1175/2011JCLI3621.1.

Enomoto, T., B. J. Hoskins, and Y. Matsuda, 2003: The formation mechanism of the Bonin high in August. Quart. J. Roy. Meteor. Soc., 129, 157-178, https://doi.org/10.1256/qj.01.211.

Feldstein, S. B., 2007: The dynamics of the North Atlantic Oscillation during the summer season. Quart. J. Roy. Meteor. Soc., 133, 1509-1518, https://doi.org/10.1002/QJ.107.

Folland, C. K., J. Knight, H. W. Linderholm, D. Fereday, S. Inesen, and J. W. Hurrell, 2009: The summer North Atlantic Oscillation: Past, present, and future. J. Climate, 22, 1082-1103, https://doi.org/10.1175/2008JCLI2459.1.

Fukutomi, Y., K. Masuda, and T. Yasunari, 2004: Role of storm track activity in the interannual seesaw of summer precipitation over northern Eurasia. J. Geophys. Res., 109, D02109, https://doi.org/ 10.1029/2003JD003912.

Greatbatch, R. J., and P. Rong, 2006: Discrepancies between different Northern Hemisphere summer atmospheric data products. J. Climate, 19, 1261-1273, https://doi.org/10.1175/ JCLI3643.1.

- X. Sun, and X. Yang, 2013: Impact of variability in the Indian summer monsoon on the East Asian summer monsoon. Atmos. Sci. Lett., 14, 14-19, https://doi.org/10.1002/asl2.408.

Hong, X., and R. Lu, 2016: The meridional displacement of the summer Asian jet, Silk Road pattern, and tropical SST anomalies. J. Climate, 29, 3753-3766, https://doi.org/10.1175/ JCLI-D-15-0541.1.

- - , and S. Li, 2017: Amplified summer warming in Europe-West Asia and Northeast Asia after the mid-1990s. Environ. Res. Lett., 12, 094007, https://doi.org/10.1088/17489326/aa7909.

— — _ and — 2018: Differences in the Silk Road pattern and its relationship to the North Atlantic Oscillation between early and late summers. J. Climate, 31, 9283-9292, https:// doi.org/10.1175/JCLI-D-18-0283.1.

Hoskins, B. J., and D. J. Karoly, 1981: The steady linear response of a spherical atmosphere to thermal and orographic forcing. J. Atmos. Sci., 38, 1179-1196, https://doi.org/10.1175/15200469(1981)038<1179:TSLROA > 2.0.CO;2.

—_, and T. Ambrizzi, 1993: Rossby wave propagation on a realistic longitudinally varying flow. J. Atmos. Sci., 50, 1661-1671, https://doi.org/10.1175/1520-0469(1993)050<1661: RWPOAR $>2.0 . \mathrm{CO} ; 2$.

Hu, K., G. Huang, R. Wu, and L. Wang, 2018: Structure and dynamics of a wave train along the wintertime Asian jet and its impact on East Asian climate. Climate Dyn., 51, 4123-4137, https://doi.org/10.1007/s00382-017-3674-1.

Huang, R., and F. Sun, 1992: Impacts of the tropical western Pacific on the East Asia summer monsoon. J. Meteor. Soc. Japan, 70, 243-256, https://doi.org/10.2151/jmsj1965.70.1B_243.

Iwao, K., and M. Takahashi, 2006: Interannual change in summertime precipitation over northeast Asia. Geophys. Res. Lett., 33, L16703, https://doi.org/10.1029/2006GL027119.

_ , and _ 2008: A precipitation seesaw mode between Northeast Asia and Siberia in summer caused by Rossby waves over the Eurasian continent. J. Climate, 21, 2401-2419, https://doi.org/10.1175/2007JCLI1949.1.

Kalnay, E., and Coauthors, 1996: The NCEP/NCAR 40-Year Reanalysis Project. Bull. Amer. Meteor. Soc., 77, 437-471, https:// doi.org/10.1175/1520-0477(1996)077<0437:TNYRP>2.0.CO;2.

Kobayashi, S., and Coauthors, 2015: The JRA-55 reanalysis: General specifications and basic characteristics. J. Meteor. Soc. Japan, 93, 5-48, https://doi.org/10.2151/jmsj.2015-001.

Kosaka, Y., and H. Nakamura, 2006: Structure and dynamics of the summertime Pacific-Japan teleconnection pattern. Quart. J. Roy. Meteor. Soc., 132, 2009-2030, https://doi.org/10.1256/ qj.05.204.

,,-- M. Watanabe, and M. Kimoto, 2009: Analysis on the dynamics of a wave-like teleconnection pattern along the summertime Asian jet based on a reanalysis dataset and climate model simulations. J. Meteor. Soc. Japan, 87, 561-580, https://doi.org/10.2151/jmsj.87.561.

, S.-P. Xie, and H. Nakamura, 2011: Dynamics of interannual variability in summer precipitation over East Asia. J. Climate, 24, 5435-5453, https://doi.org/10.1175/2011JCLI4099.1.

Lee, E., J. Jhun, and C. Park, 2005: Remote connection of the Northeast Asian summer rainfall variation revealed by a 
newly defined monsoon index. J. Climate, 18, 4381-4393, https://doi.org/10.1175/JCLI3545.1.

Li, J., and C. Ruan, 2018: The North Atlantic-Eurasian teleconnection in summer and its effects on Eurasian climates. Environ. Res. Lett., 13, 024007, https://doi.org/10.1088/1748-9326/ aa9d33.

Li, X., and R. Lu, 2017: Extratropical factors affecting the variability in summer precipitation over the Yangtze River basin, China. J. Climate, 30, 8357-8374, https://doi.org/10.1175/JCLID-16-0282.1.

— precipitation between the Yangtze River basin and the tropical western North Pacific during summer. Adv. Atmos. Sci., 35, 1231-1242, https://doi.org/10.1007/s00376-018-7304-6.

Lin, Z., 2014: Intercomparison of the impacts of four summer teleconnections over Eurasia on East Asian rainfall. Adv. Atmos. Sci., 31, 1366-1376, https://doi.org/10.1007/s00376-014-3171-y. , 2019: The South Atlantic-South Indian Ocean pattern: A zonally oriented teleconnection along the Southern Hemisphere westerly jet in austral summer. Atmosphere, 10, 259, https://doi.org/10.3390/atmos10050259.

, R. Lu, and R. Wu, 2017a: Weakened impact of the Indian early summer monsoon on North China rainfall around the late 1970s: Role of basic-state change. J. Climate, 30, 79918005, https://doi.org/10.1175/JCLI-D-17-0036.1.

— F. Liu, B. Wang, R. Lu, and X. Qu, 2017b: Southern European rainfall reshapes the early-summer circumglobal teleconnection after the late 1970s. Climate Dyn., 48, 3855-3868, https://doi.org/10.1007/s00382-016-3306-1.

Lu, R., 2004: Associations among the components of the East Asian summer monsoon system in the meridional direction. J. Meteor. Soc. Japan, 82, 155-165, https://doi.org/10.2151/ jmsj.82.155.

__ _ and B. Dong, 2001: Westward extension of North Pacific subtropical high in summer. J. Meteor. Soc. Japan, 79, 1229-1241, https://doi.org/10.2151/jmsj.79.1229.

_ J. J. Oh, and B. J. Kim, 2002: A teleconnection pattern in upper-level meridional wind over the North African and Eurasian continent in summer. Tellus, 54A, 44-55, https:// doi.org/10.3402/tellusa.v54i1.12122.

Nakamura, H., and T. Fukamachi, 2004: Evolution and dynamics of summertime blocking over the Far East and the associated surface Okhotsk high. Quart. J. Roy. Meteor. Soc., 130, 1213-1233, https://doi.org/10.1256/qj.03.101.

Nitta, T., 1986: Long-term variations of cloud amount in the western Pacific region. J. Meteor. Soc. Japan, 64, 373-390, https://doi.org/10.2151/jmsj1965.64.3_373.

- 1987: Convective activities in the tropical western Pacific and their impact on the Northern Hemisphere summer circulation. J. Meteor. Soc. Japan, 64, 373-390, https://doi.org/10.2151/ jmsj1965.65.3_373.

North, G. R., T. L. Bell, R. F. Cahalan, and F. J. Moeng, 1982: Sampling errors in the estimation of empirical orthogonal functions. Mon. Wea. Rev., 110, 699-706, https://doi.org/ 10.1175/1520-0493(1982)110<0699:SEITEO > 2.0.CO;2.

Sato, N., and M. Takahashi, 2006: Dynamical processes related to the appearance of quasi-stationary waves on the subtropical jet in the midsummer Northern Hemisphere. J. Climate, 19, 1531-1544, https://doi.org/10.1175/JCLI3697.1.

Song, F., T. Zhou, and L. Wang, 2013: Two modes of the Silk Road pattern and their interannual variability simulated by
LASG/IAP AGCM SAMIL2.0. Adv. Atmos. Sci., 30, 908921, https://doi.org/10.1007/s00376-012-2145-1.

Sun, J., and H. Wang, 2012: Changes of the connection between the summer North Atlantic Oscillation and the East Asian summer rainfall. J. Geophys. Res., 117, D08110, https://doi.org/ 10.1029/2012JD017482.

Takaya, K., and H. Nakamura, 2001: A formulation of a phaseindependent wave-activity flux for stationary and migratory quasigeostrophic eddies on a zonally varying basic flow. J. Atmos. Sci., 58, 608-627, https://doi.org/10.1175/ 1520-0469(2001)058<0608:AFOAPI > 2.0.CO;2.

Wakabayashi, S., and R. Kawamura, 2004: Extraction of major teleconnection patterns possibly associated with the anomalous summer climate in Japan. J. Meteor. Soc. Japan, 82, 1577-1588, https://doi.org/10.2151/jmsj.82.1577.

Wang, Y., 1992: Effects of blocking anticyclones in Eurasia in the rainy season (meiyu/baiu season). J. Meteor. Soc. Japan, $\mathbf{7 0}$, 929-951, https://doi.org/10.2151/jmsj1965.70.5_929.

Wang, Z., S. Yang, N. Lau, and A. Duan, 2018: Teleconnection between summer NAO and east China rainfall variations: A bridge effect of the Tibetan Plateau. J. Climate, 31, 6433-6444, https://doi.org/10.1175/JCLI-D-17-0413.1.

Wu, R., 2002: A mid-latitude Asian circulation anomaly pattern in boreal summer and its connection with the Indian and East Asian summer monsoons. Int. J. Climatol., 22, 1879-1895, https://doi.org/10.1002/joc. 845 .

Wulff, C. O., R. J. Greatbatch, D. I. V. Domeisen, G. Gollan, and F. Hansen, 2017: Tropical forcing of the summer East Atlantic pattern. Geophys. Res. Lett., 44, 11166-11173, https://doi.org/ 10.1002/2017GL075493.

Xie, S., and Y. Kosaka, 2016: Interannual variability and predictability of summer climate over the Northwest Pacific and East Asia. Dynamics and Predictability of Large-Scale, High-Impact Weather and Climate Events, J. Li et al., Eds., Cambridge University Press, 333-342.

Xu, K., R. Lu, B. Kim, J. Park, J. Mao, J. Byon, R. Chen, and E. Kim, 2019: Large-scale circulation anomalies associated with extreme heat in South Korea and southern-central Japan. J. Climate, 32, 2747-2759, https://doi.org/10.1175/ JCLI-D-18-0485.1.

Xu, P., L. Wang, and W. Chen, 2019: The British-Baikal corridor: A teleconnection pattern along the summertime polar front jet over Eurasia. J. Climate, 32, 877-896, https://doi.org/10.1175/ JCLI-D-18-0343.1.

Yang, X., 1992: Observational study of teleconnections in the geopotential height during the Northern Hemisphere summer (in Chinese). Chin. J. Atmos. Sci., 16, 513-521.

— Northern Hemisphere summertime teleconnection patterns (in Chinese). J. Meteor. Sci., 12, 119-127.

Yasui, S., and M. Watanabe, 2010: Forcing processes of the summertime circumglobal teleconnection pattern in a dry AGCM. J. Climate, 23, 2093-2114, https://doi.org/10.1175/ 2009JCLI3323.1.

Yoon, J., and S. Yeh, 2010: Influence of the Pacific decadal oscillation on the relationship between El Niño and the Northeast Asian summer monsoon. J. Climate, 23, 4525-4537, https:// doi.org/10.1175/2010JCLI3352.1.

Zhou, F., R. Zhang, and J. Han, 2019: Relationship between the circumglobal teleconnection and Silk Road pattern over Eurasian continent. Sci. Bull., 64, 374-376, https://doi.org/ 10.1016/j.scib.2019.02.014. 